\title{
Human vs. Nonhuman: Environmental Issues and Concerns in AmitavGhosh'sThe Hungry Tide
}

\author{
Marie Josephine Aruna $(\mathrm{PhD})^{1}$, E. Devabalane $(\mathrm{PhD})^{2}$ \\ ${ }^{1}$ Department of English, Bharathidasan Govt. College for Women (Autonomous)Puducherry, India. \\ ${ }^{2}$ Department of Tourism and Travel Management, Tagore Arts College, Pondicherry Central \\ University, Puducherry, India.
}

\begin{abstract}
AmitavGhosh, an ace story teller in his text The Hungry Tide discusses on a vast canvas the questions of environmental issues regarding the Sundarbans, drawing from varied sources of factual knowledge. He combines the art of nature writing and fiction at once illuminating the struggle between human and animal both forming an integral part of Nature. Ghosh engages himself in the rhetorics of storytelling weaving fiction and fact, using the pretext of Nature and its environment as the foundation from which to study the politics of human life. In fact, Ghosh had also written an essay titled 'Folly in the Sundarbans' in 2004 wherein he raises the voice of an environmentally conscious writer expressing his concern over the Sahara India Pariwar's grand plan of opening up the unknown regions of the Sundarbans, to human onslaught in the name of eco-tourism, which might have led to anthropogenic infringement of the pristine islands of the region. Any act of globalizing the local must necessarily come with accountability is what the author aims at.

This paper seeks to identify the core environmental issues of the Sundarbans, its peoples, habitats, tigers, and dolphins, natural and manmade calamities that represent the entire ecological systems of the archipelago rich in its biodiversity and life forms unique in the whole world. The relationship between varied disciplines such as Literature and Environmental Studies has been harmoniously reintegrated by Ghosh so as to explore possibilities of ethical evaluation of human responsibility towards our environment of which we too are an integral part. In the bargain, the writer has taken significant efforts to give a clarion call towards the understanding and conservation of life in the Sundarbans.
\end{abstract}

Keywords: Sundarbans, survival, accountability, tiger, dolphins, conservation, biodiversity

Conservation is a state of harmony between men and land. By land is meant all of the things on, over, or in the earth. Harmony with land is like harmony with a friend; you cannot cherish his right hand and chop off his left. That is to say, you cannot love game and hate predators; you cannot conserve the waters and waste the ranges; you cannot build the forest and mine the farm. The land is one organism. Its parts, like our own parts, compete with each other and co-operate with each other. The competitions are as much a part of the inner workings as the co-operations. You can regulate them-cautiously—but not abolish them.

-Aldo Leopold

\section{Introduction}

Literature is basically defined as that medium which serves to mirror life in all its facets and of recent times it concerns itself with the portrayal of the relationship between the human world and its physical environment, along with the constantly changing face of human connectivity with the natural world. For long man's attitude to nature had been based on master/ slave theory. Man for centuries had been the master of all that he surveyed, believed in the existence of Nature for the purpose of his sole utilization. Therefore he endeavored upon its exploitation. Now has come the time when overuse of environment has led to depletion, destruction and annihilation of the face of earth to an unrecognizable state that has resulted in the phenomenon of climate 
change. Nature has started paying back humankind in the severest manner. Humanity has to rethink, reevaluate and redesignate its relationship with its surroundings by acknowledging the fact that we are part of our environment and in no way superior to it, and at once need to concede every other organism its right to be. In this context the interdisciplinary approach to the comprehending of human- earth interface as a whole, "Ecocriticism begins from the conviction that the arts of imagination and the study thereof - by virtue of their grasp of the power of word, story, and image to reinforce, enliven, and direct environmental concern - can contribute significantly to the understanding of environmental problems: the multiple forms of eco degradation that afflict planet Earth today" [1](Buell et al, 2011).

The Hungry Tide (2004) by AmitavGhosh is fundamentally a study of the Sundarbans, a unique and immense archipelago home to several thousand species including the human and nonhuman, designated by the UNESCO as a World Heritage Site and Biosphere Reserve. Based on Ghosh's reactions in his essay 'Folly in the Sundarbans', against the Sahara India Pariwar, an industrial house's proposal to build a mega tourism project in the area, he subsequently wrote the fictional work wherein he makes a case for this world's richest mangrove forests of the delta. The very geographical landscape, the Sundarbans forming the backdrop of the novel is constantly flowing in the process of making and remaking its territories, symbolizing the ever shifting nature of the life in the delta. Its narrative is as vast as the changing tides of the river. The lives of three of its major characters caught in the tide of life, brings to light the unfathomed recesses of the human spirit, which never gets boggled in the predicament of survival of the fittest between nature and man. The role of the human vs. non human in terms of subject/object relations of contesting power paradigms is frequently interchanged. In combining fiction with nonfictional Nature writing that is generally defined as writing about the natural environment and that which often draws heavily on scientific information and facts about the natural world, Ghosh describes the Sundarbansin The Hungry Tide in such a manner:

There are no borders here to divide fresh water from salt, river from sea. The

tides reach as far as three hundred kilometers inland and every day thousands of acres of forest disappear underwater only to re-emerge hours later. . . When the tides create new land, overnight mangroves begin to gestate, and if the conditions are right they can spread so fast as to cover a new island within a few short years.

A mangrove forest is a universe unto itself ... Mangrove leaves are tough and leathery, the branches gnarled foliage often impassably dense. Visibility is short and the air still and fetid ... Every year dozens of people perish in the embrace of that dense foliage, killed by tigers, snakes and crocodiles. [3] (7-8)

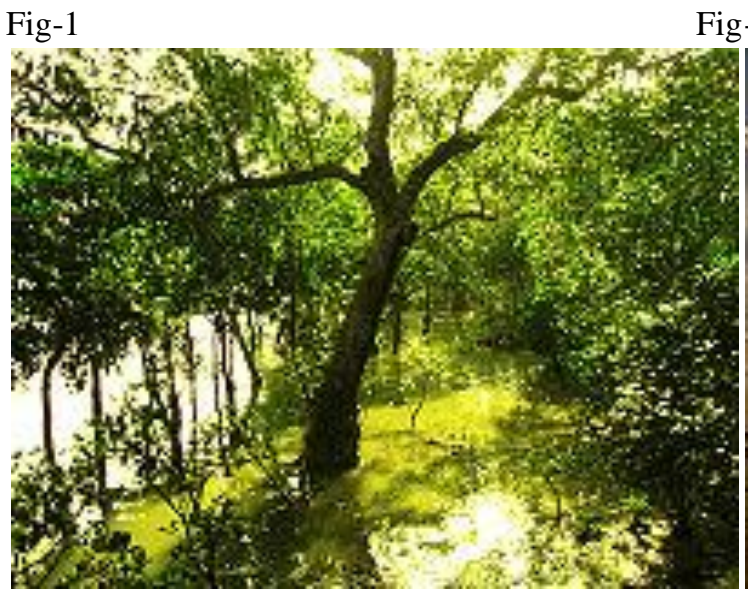

Fig-2

The Sundari Tree

The mudflats

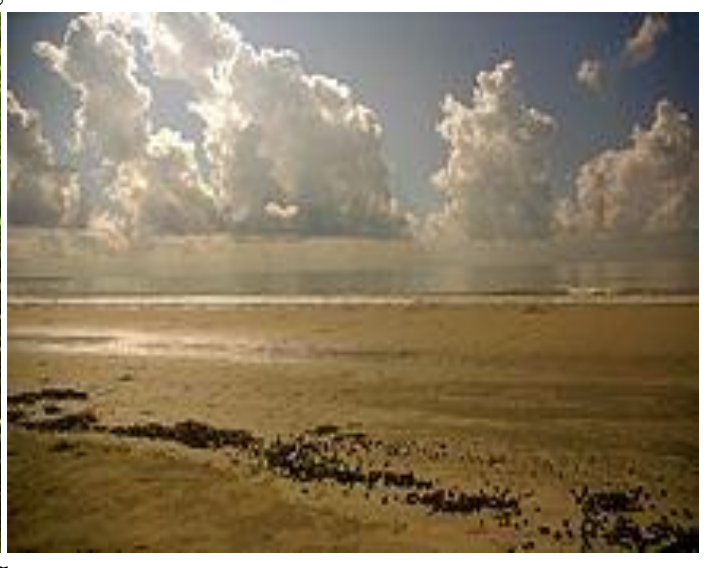




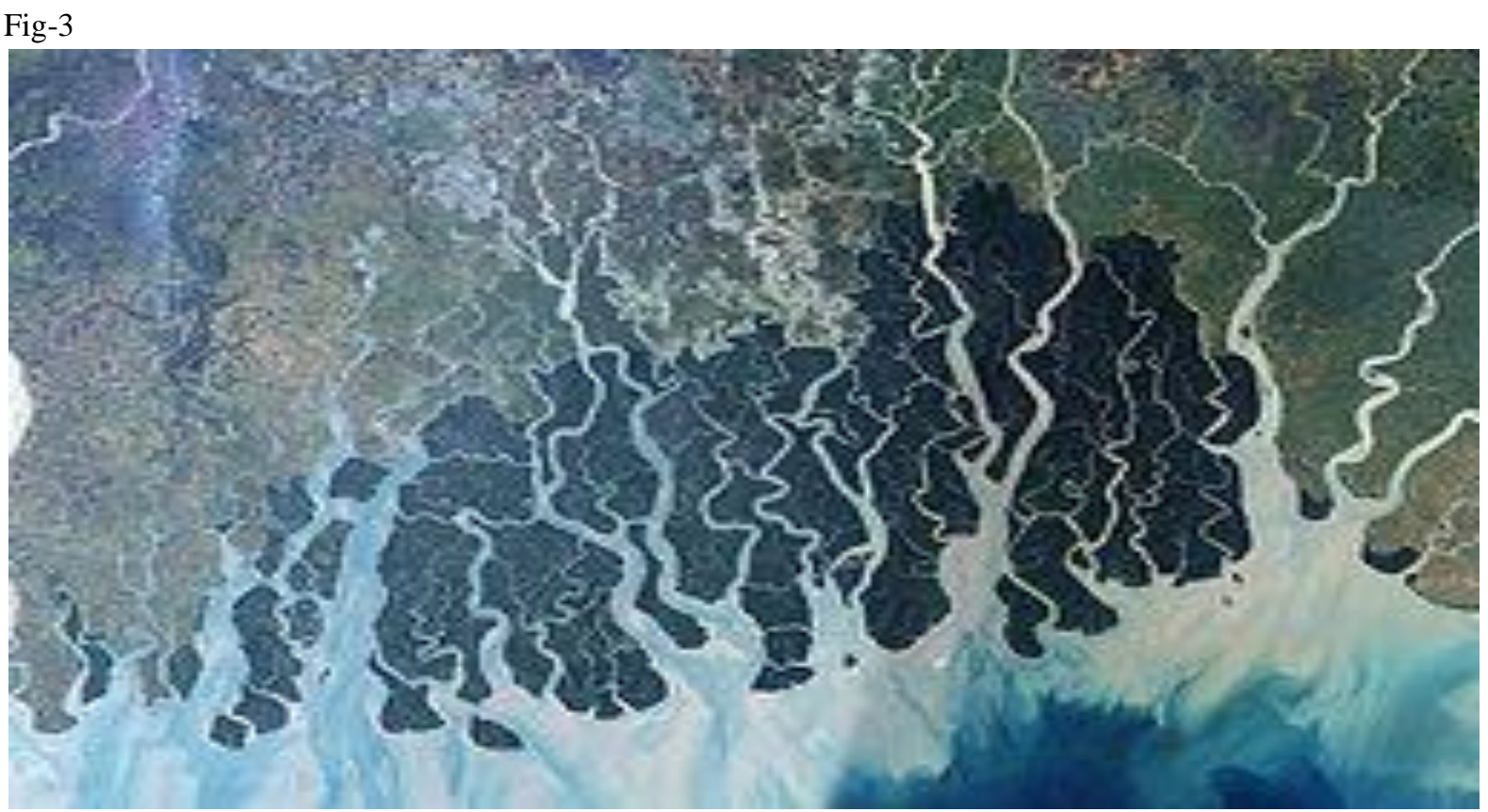

satellite image of Sundarbans released by NASA Earth Observatory

As the above figures (1, 2, and 3 sourced from en.wikipedia.org/wiki/Sundarbans) reveal the Sundarbans or 'beautiful forest' is said to derive its name from the predominant presence of the common species of mangrove -the sundari tree whose spread protects the entire region from the fury of cyclonic destructions at the same time providing stability to the whole region by preventing erosion due to tidal action. The second one shows the mudflats formed in between the tides and the $3^{\text {rd }}$ one, a satellite picture shows the rivers of the delta that Ghosh describes so:

They number in the thousands, these islands; some are immense and some no

larger than sandbars; some have lasted through recorded history while others were washed into being just a year or two ago. . . The rivers' channels are spread across the land like a fine-mesh net, creating a terrain where the boundaries between land and water are always mutating, always unpredictable. Some of these channels are mighty waterways, so wide across that one shore is invisible from the other; others are no more than two or three kilometers long and only a few hundred meters across ... when these channels, it is often in clusters of four, five or even six: at these confluences, the water stretches to the far edges of the landscape and the forest dwindles into a distant rumour of land echoing back from the horizon.[3] (The Hungry Tide6-7)

In giving a graphic description of the unfriendly and shifting nature of the Sundarbans, the text uncovers several issues related to life and existence on this delta with its diverse ecosystem in which both man, animal and other beings strive for their own eco-space thereby trying to find their means of survival. On the one hand we are told of the everyday problems of living from the human point of view, on the other the nonhuman creatures of which the most powerful of the species the tiger has to conflict with man, the ever depleting richness of the biodiversity due to salinity sounding the death knell of several rare species and yet the ecosystem is home to the Gangetic and Irrawaddy dolphins, crocodiles, deers etc., with other fauna and flora at the point of extinction. For every living creature thus it is a struggle that is at odds with Nature and simultaneously with other beings as well. 


\section{Issues and Concerns}

Piya, a cetologist in Ghosh's text an American of Indian origin with the help of the native Fokir, the indigenous guide is on her field study, on the trail of the Irrawaddy dolphin (Orcaellabrevirostris). The figures (4\&5), below sourced from www.guardian.co.uk>environment.marinelife, andzeenews.india.com/Bangladesh/Sundarbans

Fig 4

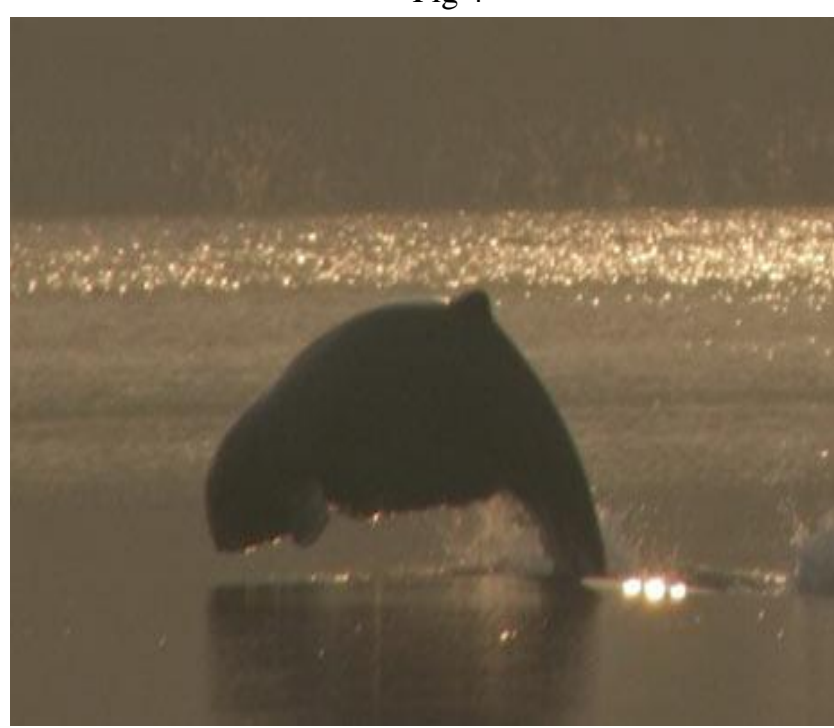

Irrawaddy Dolphins- Orcaellabrevirostris
Fig 5

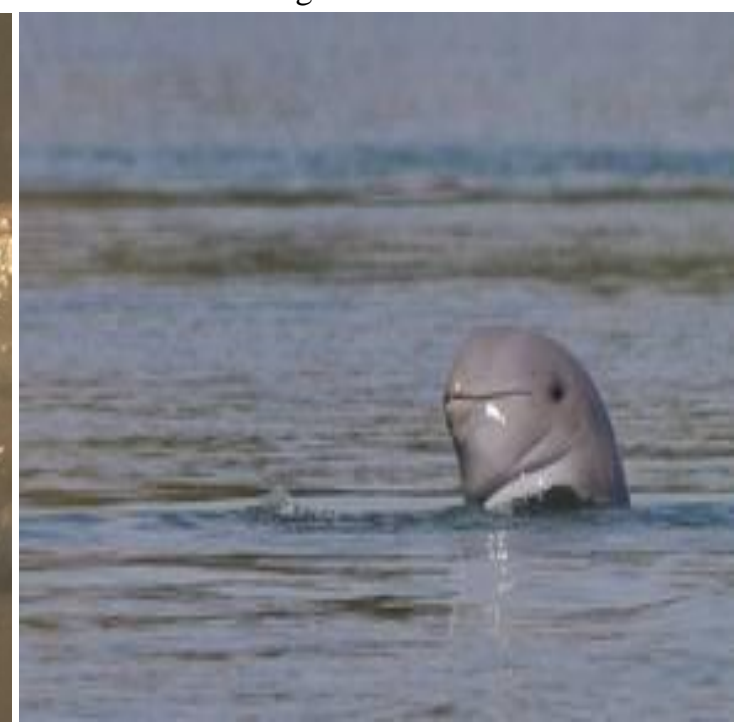

show the Irrawaddy dolphins, that Piya sights a group of seven Orcaella and describes the behavioral pattern of one of the smallest in the group, a calf that as she observed, "coming to the surface in a 'corkscrew' pattern with its little head protruding out of the water-an indication that it still had to learn to breathe smoothly" [3](The Hungry Tide114). This mammalian species is considered to be critically endangered and Piya believes that trying to decipher the movements of the Orcaella adapting itself to the tidal ecology might provide clues to conservation of this endangered species. She also gets to learn how these dolphins cooperate with the humans in their cast-net fishing. In that the Irrawaddy dolphins serve to increase the amount of fish caught by the fishermen thereby proving themselves to be economically valuable to the human lot. She had watched how in the Mekong river once "they had herded a school of fish into shallow water and the hundred creatures had buried themselves in the mud, in a futile effort to evade their pursuers" [3](167). The net pushes a great number of fish to the floor of the river that enables the dolphins have their fill while the fishermen their catch. Piya wonders: "Did there exist anymore remarkable instance of symbiosis between human beings and a population of wild animals?" [3](168). Even Fokir explains to Piya and Kanai how he knew all about the dolphins and where they go. As a small boy his mother Kusum had told him stories about the dolphins in Garjontola, of how they were Bon Bibi's messengers and brought news of the rivers and floods. They were almost his friends. In fact the Gangetic dolphins (Platanistagangetica) which Piya sights later on helps her to understand a storm brewing with their peculiar behavior because of their nature of being very sensitive to atmospheric pressure. Without thinking she's able to know the approaching storm [3](367). As Aldo Leopold, the environmentalist suggests the competition and the cooperation exists but is cautiously balanced between man and animal. Each has a worthy role to play in the larger canvas of the bionetwork. Piya also comes across the estuarine crocodiles apart from smaller creatures like the horseshoe crabs. She remembers how a study of the Sundarbans revealed the proliferation of aquatic life due to the very unusual composition of the water itself:

The waters of river and sea did not intermingle in this part of the delta; rather,they interpenetrated each other, reating hundreds of different ecological niches, with streams of fresh water running along the floors of some channels, creatingvariations of salinity and turbidity. These micro-environments were like balloonssuspended in the water, and they had their own patterns of flow . . Each balloonwas a floating biodome, filled with ndemic fauna and flora ... Thisproliferation of environments was responsible for creating 
and sustaining adazzling variety of aquatic life forms-from the gargantuan crocodile tomicroscopic fish. [3](125)

It thus has an extremely rich diversity of aquatic and terrestrial flora and fauna while its productive ecosystem acts as a natural fish nursery. However this rich biosphere is in danger of being exploited even more as a result of anthropogenic intervention in the form of globalization, economic development and eco-tourism. The Sahara India Pariwar that had to shelve its multimillion project proposal of creating an eco-village, floating restaurants, wild life tourism and several water ways in the region due to strong objections raised by environmentalists, and Ghosh's book The Hungry Tide that served to enlighten even people who were not involved in environmental studies, and the media together contributed to the saving of the region from the clutches of the mammoth 'global tiger'. But ironically only one third of Sundarbans delta is on Indian side whereas two thirds of it lies in Bangladesh. In 2012 Sahara has signed a MoU with the Bangladesh government for promoting business there and one of its goals is to develop tourism in the Sundarbans as its Chairman is quoted as telling The Daily Star about his proposal: "That project can be initiated here as the larger part of the Sundarbans falls in Bangladesh,"[6] ( Oct 2012).We need to wait and watch how things turn out what with the most recent sightings of nearly 6000 rare Irrawaddy dolphins spotted along the Bangladesh coast as reported by [7]The Guardian in 2009. The region needs to be protected all the more from such human infringement, as the incident in the novel is highlighted when Piya and Fokir on one of their forays in to the Garjontola are shocked to find the carcass of the calf that she had been happy to witness at the first instance of spotting the dolphin along with its mother. She learns that the propeller of one of the fast moving motorboats of the coastguard or the police or even the forest officials had hit the calf and caused its death. Fokir also points out that he had come across three such instances along the river that emphasizes the need for conservation and habitat preservation.

At home in the Sundarbans the royal Bengal tiger (fig 6), sourced from the West Bengal Tourism website has been constituted as endangered species and conserved under the Project Tiger. The Sundarbans is the only mangrove forest in the world that houses the tiger with the highest tiger population in the world being found in this tiger reserve. As several studies show the conservation of this majestic animal has been a privileged one over the poor humans of the place. Becoming a world heritage site has put the tigers in the center while at

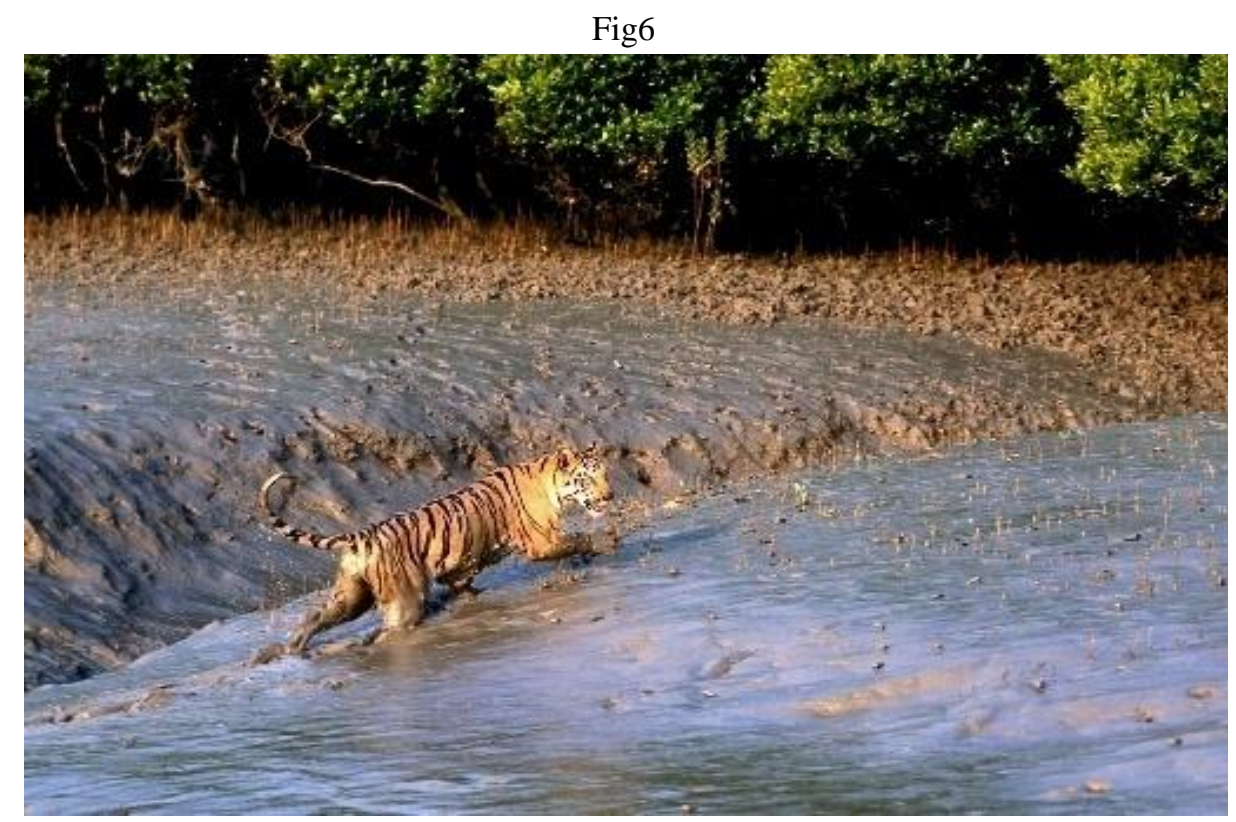

The Royal Bengal Tigerthe same time marginalizing the peoples of the islands. With the increase in tiger population, there raises the question of how much space has been actually earmarked for the movement of the growing numbers of the species. There is the danger of tigers wandering into human space/habitation and end up eating men, women, children and cattle. An incident described by Ghosh in his text sets one wondering at the credibility of conservation of one particular species at the cost of another. Piya, Kanai, Fokir and Horen 
witness the killing of a tiger by a mob. The tiger had already encroached upon human habitation having killed a buffalo and revisiting a second time is caught by the furious mob waiting to kill it:

When they neared the crest of the embankment Horen pointed to a large mark in

the dust and gestured to indicate that this was the place from which the animal had surveyed the village and picked its prey. . . By the light of the torches they saw that the village was made up of clusters of mud huts, so arranged as to run parallel to the embankment. Directly in front of them, a few hundred meters away, was a small mud-walled structure with a thatched roof. More than a hundred people had gathered around this little hut: most of them were men and many were armed with sharpened bamboo poles: they were plunging in to the hut over and again. Their faces were contorted in such a way that they seemed to be in the grip both of extreme fear and uncontrollable rage. Many of the women and children in the crowd were shrieking, Maar! Maar! Kill! Kill!" [3](291-

292)

The predator had already killed two people, and many livestock of the village, and when Piya wants to save the animal she is shocked to realize both Fokir and Kanai too join the mob in setting fire to the animal. Piya sensitive to the rights of animals to be does not understand the tricky situation wherein human beings were fighting for survival against this animal. And ironically the next day is a day of arrests, fines and beating from the khaki-uniformed forest guards. The New Sunday Express in its [5]February 32013 issue had published news regarding mob attack on the tiger. The year 2012 has been considered a bad year for tigers as nearly 88 of them have been killed on straying into human dominated habitats. The Wildlife authorities have now recommended Section 144of $\mathrm{CrPc}$ to be extended to the SOP (Standard Operating Procedure), so as to prevent the mobs around tigers that enter their landscapes. When there is no clear line of demarcation between human habitation and tiger land such instances of loss of life on both sides will occur as a result of man-animal conflict. The man -animal conflict has to be viewed seriously as the Sundarbans tiger is a confirmed man eater and as Chakrabarti discusses in his article on 'Local People and the Global Tiger: An Environmental History of the Sundarbans:

$\ldots$ the setting up of a tiger reserve and its maintenance in this unique mangrove

swamp involved dealing with a whole range of unknowns. It was imperative to

find answers to a number of questions, such as how many square kilometers

should be assigned per tiger, what kind of plants would be preferable, how to

ensure the availability of the tigers' natural food without causing any harm to the

biodiversity of this unique zone, and so on. The Sundarbans Project Tiger itself

was a project for the managing of the unknown, but in its turn has triggered off

new, unanticipated unknowns. [2](Chakrabarti 2011).

The Hindu OP-ED in its Jan14, 2012 issue discusses the issue and suggests that "the answer to this human-tiger conflict lies in good conservation science and in mitigation measures that help people co-exist with the carnivores at the landscape level and the relocation of people from tiger territory with handsome compensatory packages is a superior alternative to crisis management techniques, providing a wider prey base within its habitation will ensure the tiger not seeking the cattle. And creating wider undisturbed habitat will benefit both"[8]. Nature seems to add to the problem of tiger man conflict as recently reported by the Hindu in its issue of January 11, 2013, that tells about the shrinking mangrove forests of the Sundarbans that poses a great danger to the endangered species. Nearly 200 meters of the coastal vegetation disappear every year, due to global warming, cyclones, tidal waves and human development. Native to nearly 500 species of reptiles, fish bird and mammals including the Royal Bengal tiger the whole region is fast depleting. The Zoological Society of London's tiger conservationist is quoted as saying: "The Sunderbans is a critical tiger habitat; one of only a handful of remaining forests big enough to hold several hundred tigers. To lose the Sunderbans would be to move a step closer to the extinction of these majestic animals." [9](The Hindu, Business Line, 2013)

The history of human settlement in the Sundarbans as Ghosh writes in his book begins with S'Daniel Hamilton, a Scot, who had bought ten thousand acres of the tide country from the British. These islands initially were only forests with no people or embankments, but tigers, crocodiles, sharks and leopards. The first settlers arrived since the 1920's, people had been pouring in from different parts of India and Bangladesh to settle in the tide 
country. After the famine of 1942 the whole region was devastated while hunger and catastrophe became a way of life. "They learnt that after decades of settlement, the land had still not been wholly leached of its salt. The soil bore poor crop sand could not be farmed all year round. . Hunger drove them to hunting and fishing, and the results were often disastrous ... thousands risked death in order to collect meager quantities of honey, wax, firewood, and the sour fruit of the kewra tree. No day seemed to pass without news of someone being killed by a tiger, a snake or a crocodile" [3](The Hungry Tide79). In such a condition do Nilima and Nirmal, social activists and Kanai's aunt and uncle start the NGO Badabon Development Trust to help the poor people providing those basic amenities of drinking water, electricity, education and medical help.Nirmal keeps a notebook in which he records the place, the people, the history and the environment with the idea of compiling a book about the tide country. Having come there in his youth after thirty years in the late70's he finds that the millions of swarming crabs, birds were fast disappearing, the fish were dwindling, and the land from day to day was being reclaimed by the sea. He also records the happenings at Morichjhapi where the settlers were being forced to relocate to the main lands and vacate the forests. He writes how Kusum explains the situation when the police laid siege to Morichjhapi and its people who were starved by the authorities which action might force them to quit the island:

the worst part was not the hunger or the thirst. It was to sit here, helpless, and listen to the policemen making their announcements, hearing them say our lives, our existence, was worth less than dirt or dust. This island has to be saved for its trees, it has to be saved for its animals, it is a part of a reserve forest, it belongs to a project to save tigers, which is paid for by people all around the world ... this whole world has become a place of animals, and our fault, our crime was that we were just human being, trying to live as human beings always have, from the water and the soil. No human being could think this a crime unless they have forgotten that this is how humans have always lived-by fishing, by clearing land and by planting the soil. [3](261-262)

Ghosh makes a case for the indigenous inhabitants who were considered a direct threat to the lands, forests and reserve areas and who in turn were dispossessed of their homes to accommodate more space for the tigers. These peoples had to fight against not only the unstable and menacing natural environment, the cyclones, tigers and crocodiles but also other powerful human beings. Contrary to the belief of authorities that the peoples of these mangroves contributed to its destruction, the indigenous people in fact had their own belief systems which could be tapped for knowledge production about these regions. The story of Bonbibi in the text rather reflects the need to respect the environment despite its inconsistent and intimidating nature. The story also has its own ethical and didactic purpose of laying emphasis on the restrained conduct of people both in their relationship with other people as well with their environment. It seeks to regulate their actions and attitudes thereby inculcating ecological and social values in their everyday dealings with nature and other beings sustaining their very existence amidst the unknown. After all humans are also organs of the environment and need to have their own space.

There have been sustained efforts from various quarters both governmental and nongovernmental to save the Sundarbans in terms of conservation and habitat restoration as part of restoring the entire ecosystem of the region. But the ground situation in this uniquely fragile mangrove forests is that climate change and global warming has started taking its toll on the archipelago. Recent studies have shown how there is loss of large landmass of the Sundarbans, shrinking of its mangrove forests, rise in sea water level causing submergence of cultivable lands, sometimes an entire island. Peoples of the Sundarbans are often relocated after cyclonic storms when their homes and lands are washed under the sea. Human interferences have been too much that vegetations were cleared for their settlement that the region is often prone to frequent changes in weather conditions. The waters exploited for fishing, and the increase in the salinity of water, has also resulted in loss of species and fall in fish catch. Erosion of the coastal lands has also resulted in climatic disasters in the Sundarbans and has made it even more vulnerable. The loss after a cyclone in such areas cannot be quantified exactly in terms of life both human and nonhuman. In spite of the ambiguities in human -animal conflict where the subject-object positions are always overturned, they are equally at the mercy of a bigger force of nature that seeks to destroy both 
without any preference.Therefore conserving endangered species in the ecosystem should not be done at the cost of the livelihoods of the economically backward local peoples. The Sunderbans is one of the rarest environmental treasure trove and natural resources of India that needs to be protected and conserved for future generations. Special policies and measures should be made to address the ecological problems in the Sundarbans.

- Local people need to be sensitized on environmental issues of global warming and its impact on their islands

- Providing basic amenities like water, electricity and health requirements

- Eco-friendly projects to be implemented with the consent of locals

- To minimize man-animal conflict, and prevent people from entering forests frequently, alternate income and resource should be provided

- Role of government to undertake poverty mitigating measures

- Calculated development activities undertaken

- Tourists to the area to be sensitized about the environment

- Channelizing of tourist inflow to the region, thereby control garbage production

- Involving educational institutions, industries and NGO's to work with the people of the area towards community development and habitat maintenance

- Tapping their ingenious knowledge systems and using it for knowledge production of the region

\section{Conclusion}

The Sundarbans is only a case in point. There are several other endangered ecosystems on planet earth. It is the moral responsibility and accountability on the part of every human to conserve our environment, as it is increasingly becoming a threatened environment for each and all of its members, human or nonhuman, where each requires in its own space to be. Animals are more eco-sensitive than humans. Global warming is responsible for the fast depleting spaces thereby shrinking animal, as well as human space that ends in conflict. The need of the hour is to build a future that strikes a balance between man and his surroundings, to live in harmony with his environment. If the 'here and now' is put in its place the future certainly will take care of itself. The right place to begin the change is the educational institutions of higher learning. The youth has to be tapped for its potential because it is them more than anyone else who take the environment for granted. Environmental values need to be inculcated in their minds along with the idea of the compulsory human responsibility to save planet earth. A strong curriculum has to be developed for this purpose. Of late Environmental Studies as a subject has been introduced at the tertiary level of education, though not with the expected kind of seriousness. The curriculum should not just stop with teaching concepts but by enabling them a firsthand experience of the problems and challenges facing the environment. Involving them directly in to the field, making them proactive not by just providing theoretical knowledge in campus, rather helping them practice off campus as well. Students as prospective environmental managers need to first understand their environment, taught to respect Nature, local peoples, their culture, animals and other wildlife species, and in turn to educate and sensitize others as well about the environment. As Walter Leal Filho points out about the role of higher education in his article 'Towards the Promotion of Education for Sustainability':

Meeting basic human needs now and in the future requires a major shift in

the thinking, values, and actions of all individuals and institutions in their relationship with the natural environment. This shift in mindset must be led by the higher education system because it prepares most of the people who develop and manage society's institutions, and who serve as teachers. It will require comprehensive short- and long-term educational change, necessitating unprecedented leadership and commitment by colleges, universities and professional schools. [4](Leal, 2009).

In short the well being of our environment, our planet earth is in our hands and we ought to renegotiate, and realign our relationship with it. As Piya and Kanai in Ghosh's text make deliberate decisions to conserve the peoples and environment of the Sundarbans with commitment by relocating themselves to the place. Ghosh's 
text here is a source of creating awareness/ecological consciousness and sensitizing the readers to the unique mangrove forests of the world. Including such texts in the curriculum would ensure the basic understanding of places, their environment, ecosystem, that would serve to not only sensitize young minds but also to enable them to incline their minds towards conserving and sustaining planet earth for future generations.

\section{References}

[1]. Buell, Lawrence, Karen Thornber, and UrsulaK. Heise. "Literature and Environment". Annual Reviewof Environmental Resources. 36:417-40. 2011. Web. 2 January 2013.

[2]. Chakrabarti, Ranjan.. "Local People and the Global Tiger". Global Environment. A Journal of History and Natural and Social Sciencesn. 7-8. 2011. Web. 10 January. 2013.

[3]. Ghosh, Amitav. The Hungry Tide. India: Harper Collins, 2004. Print.

[4]. Leal, Filho W. "Towards the Promotion of Education for Sustainability". www.revistaeducation.mcc/es/re2009/ 2009. Web. 20 May. 2012.

[5]. Sharma, Pratul. "The $144^{\text {th }}$ Way to Save Our Big Cats". The New Indian Express. Chennai 3 February, Puducherry Edition.www.newindianexpress.com.thesundaystandard. 2013. Web. 5 April. 2013.

[6]. The Daily Star. "Sahara to invest \$100m initially". Sat. May26, 2012. www.archive.thedailystar.net . 2012. Web. 5 April. 2013.

[7]. The Guardian. "Thousands of rare Irrawaddy Dolphins found along Bangladesh Coast". Wed 1. April. www.theguardian.co.uk. 2009. Web. 5 April. 2013.

[8]. The Hindu. "Saving People, and Tigers". Jan 14. www.thehindu.com.opinion editorial. 2012. Web. 5 April. 2013.

[9]. The Hindu Business Line. "Rapidly Shrinking Sundarbans Threat to the Bengal Tiger: Study". Jan 11. www.thehindubusinessline.com. 2013. Web. June 10.2013. 